\title{
International Business Cycles, Financial Markets and Household Production
}

\author{
Fabio Canova* \\ Universitat Pompeu Fabra, University of Modena and CEPR \\ and \\ Angel J. Ubide \\ IMF \\ This version: January 1997
}

\begin{abstract}
This paper investigates the properties of an international real business cycle model with household production. We show that a model with disturbances to both market and household technologies reproduces the main regularities of the data and improves existing models in matching international consumption, investment and output correlations without irrealistic assumptions on the structure of international financial markets. Sensitivity analysis shows the robustness of the results to alternative specifications of the stochastic processes for the disturbances and to variations of unmeasured parameters within a reasonable range.
\end{abstract}

Key words: Household Production, International Business Cycles, Taste Shocks, Consumption Correlations.

JEL Classification nos: C68, E32, F41,

*We would like to thank two anonymous referees, Steve Ambler, Finn Kydland, Eva Ortega, Morten Ravn, Randy Wright and the participants of the NBER Conference on Labor Markets at UQAM, the 1995 Colloquia on Economic Research at IGIER, Milan, the 7th Econometric Society World Meeting, Tokyo, the 1995 EEA Meeting, Prague and of seminars at EUI and Pompeu Fabra for helpful comments and suggestions. Canova acknowledges the financial support of a DGICYT grant. 
Soltanto questo, oggi, possiamo dire, cio' che non siamo, cio' che non vogliamo.

Eugenio Montale

\section{Introduction}

Since the seminal work of Kydland and Prescott (1982) and Long and Plosser (1983), many authors have investigated the properties of domestic business cycles within the framework of dynamic neoclassical general equilibrium models. In international frameworks these models have been used to study the determinants of aggregate fluctuations in open economies and the transmission of idiosyncratic shocks across countries. For example, Mendoza (1991), and Correia, Neves and Rebelo (1992) have addressed the question of what generates aggregate fluctuations in a small open economy; Backus, Kehoe and Kydland (BKK) (1992) have considered a two country-one good model to investigate the international propagation of domestic cyclical fluctuations. The basic one-good framework has been extended to include multiple sources of shocks (e.g. government spending (Ravn (1993)), multiple sources of transmission (production and consumption interdependencies (Canova and Marrinan (1996)), nontradable consumption goods (Stockman and Tesar (1994)) and the properties of these models for trade issues (J-curve, see BKK (1993), policy questions (saving and investment correlations, see Baxter and Crucini (1993) or Van Wincoop and Marrinan (1994)) and insurance schemes (see e.g. Devereux, Gregory and Smith (1992)) have also been studied. There have also been a few attempts to introduce money into these models, see e.g. Cardia (1991). Despite these efforts, there are still aspects of international data that these models fail to account for, e.g. the relative ordering of cross-country consumption and output correlations (an exception is Marrinan (1995)) and some of the quantitative properties of the models, e.g. the magnitude of the correlation between output and investment, are sensitive to the choice of unmeasured parameters.

This paper contributes to this literature by examining the properties of an international business cycle model with household production. There are several reasons why this may be an interesting undertaking. Theoretically, household production can provide a firm rationale for the presence of nontraded goods in an international business cycle model and highlight a channel through which substitution effects typical of labor and goods markets over the business 
cycle (e.g. entering the work force vs. working at home; consuming home produced or market produced goods) may be examined. Moreover, Stockman and Tesar (1994) have found that taste shocks may help to rationalize international comovements of prices. Household production shocks may also be used to justify the presence of otherwise uninterpretable taste shocks in the utility function of the representative agent of a country.

Household production appears to be an important feature of the real world. Formal and informal measures of the importance of the household sector have suggested that this sector's output represents between 20 and 50 percent of the value of measured gross national product in several OECD countries (Eisner (1988)). In addition, Hill (1985) and Juster and Stafford (1990) report that a typical US married couple spends 25 percent of their time working unpaid at home, while Bonke (1995), studying 14 different countries, finds that women work at home between 25 and 57 per cent of their time while men devote between 3 and 21 per cent of their time to household activities. These figures suggest that the inclusion of household production in a business cycle model may have important implications for our understanding of how cyclical dynamics are propagated both at a domestic and at an international level and may account for some of the unexplained aspects of the data.

Recently Benhabib, Rogerson and Wright (BRW henceforth) (1991), Greenwood and Hercowitz (1991) and Greenwood, Rogerson and Wright (GRW) (1993) examined the properties of closed economy RBC models with household production and showed that they outperform existing RBC models in matching the volatility of market output, the relative volatility of consumption and investment to market output the correlation between market hours and productivity and the cyclical properties of household and business investments. Fisher (1992) and McGrattan, Rogerson and Wright (1993) (MRW) estimated closed economy models with household production, obtaining significant estimates of household production parameters, and performed fiscal policy exercises which reach very different conclusions from those of standard models. Rios-Rull (1993) studied the cross-sectional wage, education and employment profile of workers in a model with household production and finds that lower-wage, less skilled or older individuals tend to devote more time to household activities.

To the best of our knowledge, no one has yet considered the effects of household production in an open economy framework. Our work attempts to fill this gap by asking whether it is 
possible to improve the performance of existing models by considering shocks to both market and household technologies. In particular, we are interested in knowing whether the addition of household production shocks in an otherwise standard model helps to solve three remaining puzzles of the international business cycle literature, i.e. the size of the volatility of the terms of trade, the relative magnitude of cross country consumption and output correlations and the sign and the magnitude of cross country investment correlations, without simultaneously affecting other important aspects of the model. Intuitively, the presence of household production may reduce the extent of the mismatch between theory and the data for three reasons. First, the economy displays productivity differentials across sectors in response to technology disturbances and, as argued by BRW, this tends to enlarge the volatility of market variables. Therefore, we expect to be able to generate higher variability in the terms of trade relative to models without home production. Second, with home production there is an explicit non-tradable sector in the economy and this may break the tight link between international market consumption correlations typical of models with complete international financial markets. The higher is the substitutability between consumption of market and nonmarket goods, the lower are likely to be international market consumption correlations (relative to output correlations). Third, when household production requires capital, negative shocks to the market technology may result in lower investment in the market sector both domestically and abroad, as capital is reallocated to household technologies, therefore making the cross-country correlation of market investment less negative. Similarly, with positive household technology shocks, investment in the market sectors of both countries will tend to decline leading to a positive correlation of market investments. Therefore, a combination of technology disturbances in both sectors may help to generate cross country investments correlations in the range of values observed in the data.

After this introduction, we present in section 2 an extension of the two country model of Backus, Kehoe, Kydland (BKK) (1993) where each country produces one intermediate tradable good with a market technology and one final nontradable goods produced with a household technology. Domestic and foreign intermediate goods are combined to produced a final market good which can be used for consumption and investment. Technologies are subject to productivity disturbances and require capital and labour. Since the household good can only be consumed, household production disturbances play the role of 'taste' shocks: they change the composition 
of the bundle consumed by the agents in equilibrium, the allocation of time between market and nonmarket activities and the composition of investment by sector therefore producing dynamics which are different from those generated by disturbances to the market technology. In addition, because household production is not part of measured GNP, disturbances to the household technology affect market output only to the extent that the elasticity of substitution between market and nonmarket goods is different from zero and the degree of substitution between the two types of goods is crucial for determining the properties of domestic and international transmission. This feature critically distinguishes our model from those of Stockman and Tesar (1994) or Ravn (1993) and will help us account for some of the puzzling features of the actual data.

In section 3 we describe the calibration of the model. In section 4 we first briefly discuss some features of the data and then present a quantitative analysis of three symmetric versions of the model: one where only disturbances to the market technology are present, which will serve as a benchmark; a second one where only disturbances to the household technology exist, which will give us an idea of what home production does in the model and third one, where both types of shocks are present. We show that when both types of disturbances are present, the model accounts for the relative size of cross country consumption and output correlation and the positive cross country correlation of investment while maintaining a reasonably good fit to the data in other dimensions. In section 5 we study whether the presence of asymmetries in the processes for the disturbances alters the properties of the model. We also perform sensitivity analysis to check whether the outcomes depend on the choice of unmeasured parameters or of parameters for which a wide range of empirical estimates exist. We find that the basic features of the simulations are robust to both the presence of asymmetries and to the choice of many parameters within a reasonable range. Interestingly, international comovements have a nonlinear relationship with some of the parameters. Section 6 concludes.

\section{The Model Economy}

The model we employ extends the two country setup of BKK (1993) to include household produced goods. Countries are populated by one representative agent maximizing her utility and living forever. There are no restrictions to capital movements or trade in intermediate market goods, but labor and final goods are not traded across countries. We assume that at time 
zero the two countries are equally wealthy and that agents can write international contingent contracts promising to pay a fraction of the intermediate market goods. Contingent contracts promising to pay a fraction of the household or of the final market goods are written and traded only domestically.

Preferences of the representative agent of country $h=1,2$ are given by

$$
W_{h}=E_{0} \sum_{t=0}^{\infty} \beta^{t} U_{h}\left(C M_{h t}, C N_{h t}, L_{h t}\right)
$$

where $W$ is total discounted lifetime utility, $U_{h}($.$) is the instantaneous utility function, \mathrm{E}$ is the conditional expectations operator, $\beta$ is the subjective discount factor, $C M_{h t}$ is consumption of the final market good, $C N_{h t}$ is consumption of the household good and $L_{h t}$ is leisure. The instantaneous utility is of the form:

$$
U_{h}=\frac{\left(C_{h t}^{b} L_{h t}^{1-b}\right)^{1-\tau}-1}{1-\tau}
$$

where $\mathrm{C}_{h t}=\left[a C M_{h t}^{e}+(1-a) C N_{h t}^{e}\right]^{1 / e}$ is a CES aggregator, $0 \leq a \leq 1$ is the relative weight of market goods in total consumption, $\frac{1}{1-e}$ is the elasticity of substitution between market and household goods, $0 \leq b \leq 1$ is the relative weight of consumption to leisure and $\tau$ is the risk aversion parameter. Total endowment of time is normalized to one and leisure choices are constrained by:

$$
1 \geq H N_{h t}+H M_{h t}+L_{h t} \geq 0
$$

where $H M_{h t}$ are hours worked in the market sector and $H N_{h t}$ are hours worked in the household sector at time $t$ in country $h$.

Each country $h$ specializes in the production of an intermediate market good $\mathrm{Y}_{h}$ and of a final household good $\mathrm{CN}_{h}$ using a Cobb-Douglas technology

$$
\begin{aligned}
& Y_{h t}=f\left(H M_{h t}, K M_{h t}\right)=A M_{h t} K M_{h t}^{\theta}\left(X_{h t} H M_{h t}\right)^{1-\theta} \\
& C N_{h t}=g\left(H N_{h t}, K N_{h t}\right)=A N_{h t} K N_{h t}^{\eta}\left(X_{h t} H N_{h t}\right)^{1-\eta}
\end{aligned}
$$

where $\mathrm{AM}_{h t}\left(\mathrm{AN}_{h t}\right)$ is a stationary disturbance to the market (household) sector, $\mathrm{KM}_{h t}\left(\mathrm{KN}_{h t}\right)$ is the stock of capital used in the production of the market (household) good, $\mathrm{X}_{h t}$ is a labour augmenting Hicks-neutral technological progress, assumed to grow at a common rate $\gamma-1$ across 
sectors and countries, and $\theta$ and $\eta$ are share parameters. While there is some evidence (see Greenwood and Herkowitz (1991) and MRW (1993)) that the household production function is not exactly Cobb-Douglas, the marginal gain of having a more general specification in our setup is minimal and we neglect this possibility. As in BKK (1993) we assume that $\mathrm{Y}_{h t}$ can be either used domestically or exported

$$
\begin{aligned}
& Y_{1 t}=A_{1 t}+\frac{\Pi_{2}}{\Pi_{1}} \tilde{A}_{2 t} \\
& Y_{2 t}=B_{1 t}+\frac{\Pi_{1}}{\Pi_{2}} \tilde{B}_{2 t}
\end{aligned}
$$

where $\tilde{A}_{2 t}$ and $B_{1 t}$ are exports and imports of country 1 and $\Pi_{h}$ is the share of population living in country $h\left(\Pi_{1}+\Pi_{2}=1\right)$. We let $\mathrm{A}_{2 t}=\frac{\Pi_{2}}{\Pi_{1}} \tilde{A}_{2 t}$ and $\mathrm{B}_{2 t}=\frac{\Pi_{1}}{\Pi_{2}} \tilde{B}_{2 t}$. Domestic and foreign intermediate market goods are combined to produce a final market good in each country, $\mathrm{V}_{h t}$, which can be used for consumption or investment, according to a CES technology of the form:

$$
C_{h t}+I_{h t}=V_{h t}=\left(\varpi_{1} A_{h t}^{1-\rho}+\varpi_{2} B_{h t}^{1-\rho}\right)^{\frac{1}{1-\rho}} \quad h=1,2
$$

where $1 / \rho$ is the elasticity of substitution between domestic and foreign goods and $\varpi_{1}$ and $\varpi_{2}$ are parameters regulating the domestic and foreign content of market produced final goods.

The market sector produces investment goods but the national stock of capital is used in both the market and household sectors. The law of motion of capital is:

$$
K_{h t+1}=(1-\delta) K_{h t}+I_{h t} \quad h=1,2
$$

where $\mathrm{K}_{h t}=\mathrm{KM}_{h t}+\mathrm{KN}_{h t}$ is the total stock of capital of country $h, 0<\delta<1$ is the depreciation rate, common to both sectors and countries and $\mathrm{I}_{h t}$ is total investment in country $h$. Contrary to BKK we do not introduce time to build in (9) since it complicates the setup without adding too much to the dynamics of the variables of interest. Also, contrary to standard one good models, we do not need to include adjustment costs in (9) to produce acceptable results because the presence of two goods in each country prevents the model from generating excessively large capital flows in response to technology disturbances.

Production disturbances are assumed to follow a first order Markov process

$$
Z_{t+1}=C Z_{t}+\epsilon_{t+1}
$$


where $Z_{t+1}=\left[A N_{1 t}, A N_{2 t}, A M_{1 t}, A M_{2 t}\right]^{\prime}$ and $\epsilon_{t+1} \sim N(0, V)$. This specification for the disturbances is general enough to encompass several forms of asymmetries across countries which we will discuss later on.

The relative price of imports to exports (the terms of trade) is given by (see BKK (1993)):

$$
P_{t}=\frac{\partial V_{2} / \partial B_{1 t}}{\partial V_{1} / \partial A_{1 t}}=\frac{\varpi_{2} B_{1 t}^{-\rho}}{\varpi_{1} A_{1 t}^{-\rho}}
$$

where $\frac{B_{1 t}}{A_{1 t}}$ is the import ratio in country 1 . Also, net export in country 1 relative to output is defined as $n x_{t}=\left(A_{2 t}-P_{t} B_{1 t}\right) / V_{1 t}$.

It is useful to point out that our model specification differs from those of Stockman and Tesar (1994) and Ravn (1993) since in their setups the nontraded good's output is part of the resource constraint so that a shock to the nontraded technology affects GDP directly. In our model the nontraded (household) good does not enter the computation of measured GDP so that a shock to the household sector affects GDP only to the extent that market and household goods are substitutes.

It is easy to decentralize the planner problem we have just described assuming that there are two equity each country: one which pays as dividends units of the final market good and one which pays as dividends units of the household good. These equities are not traded in international markets. Moreover, we assume there is one factor market, two goods markets (one for intermediate goods and one for final goods) and an equity market for each country. On the factor market the domestic household rents factors of production to the firms producing household and intermediate market goods and receive in exchnage factor payments. On the international market for intermediate goods, the firm producing the final goods acquire intermediate goods and combine them to produce one domestic final market good which is sold on domestic markets to domestic households. Dometic household own these firms and receive as dividends from equity ownership whatever is leftover after payments to domestic and foreign intermediate goods producing firms are made. We also assume that intermediate good producing firms are vertically integrated and own by firms producing final market goods. The household also owns the firm producing household goods and receive for its equity ownership whatever is leftover after factor payments.

The household budget constraint is: 
$c_{h t}+I_{h t}+q m_{h t} e m_{h t+1}+q h_{h t} e h_{h t+1}=w_{h t}\left(H H_{t h}+H M_{t h}\right)+r_{h t}\left(K H_{t h}+K M_{t h}\right)+q m_{h t}\left(e m_{h t}+d m_{h t}\right)+q h_{h t}\left(e h_{h t}+d h_{h t}\right.$

\section{The Calibration and the Solution of the Model}

In calibrating the parameters of the model we follow the existing practice of choosing share parameters to replicate long run averages of the data and utility parameters to match estimates obtained in previous empirical studies. The values we have selected for $\beta=0.98, \delta=0.025$, $\Pi_{1}=\Pi_{2}=0.5$ are standard and do not require discussion. To economize on parameters and because results are insensitive to this choice we set $\tau=1 . \theta$ is set to 0.36 which is, appproximately, the mean value of the share of capital in production for developed countries (see Zimmermann (1994)) and it is close to the capital share for the US, Germany and Japan (see Canova and Marrinan (1996)). To match the steady state ratio of consumption of household goods to market output (CN/Y) (0.20-0.50 according to Eisner (1988)), we set $\eta$, the share of capital in the household production function, equal to 0.08 (as in BRW) and that gives us a steady state $\mathrm{CN} / \mathrm{Y}$ ratio of 0.2631 . In a model with household production and government expenditure, GRW (1993) selected $\theta=0.29$ and $\eta=0.32$ when matching the ratio of consumer durables plus residential structures to output instead of $\mathrm{CN} / \mathrm{Y}$. Because the difference between the two values of $\eta$ appears to be significant, we will examine the sensitivity of the results to variations in this parameter in the range $[0.00,0.40]$.

The parameters $a$ and $b$ are chosen so that hours worked in the market $H M^{s s}$ equal 0.33 and hours worked at home $H N^{s s}$ equal 0.25 , which are the long run values for the USA. The values we obtain, $a=0.35$ and $b=0.63$, are similar to those used in BRW(1991). Hovewer, because $H N^{s s}$ appears to vary considerably across the major 9 OECD countries (see Bonke (1995)), we will also study if results depend on the value of $H N^{s s}$ chosen within the range $[0.00,0.36]$, which includes the value of 0.12 estimated by MRW (1993).

The choice of $e$, the parameter describing the elasticity of substitution between household and market goods in the utility function, is more problematic since empirical evidence is controversial. Recall that the closer $e$ is to zero, the smaller is the contribution of the household production 
sector to fluctuations in the market economy (see BRW (1991)). Eichenbaum and Hansen (1990) differentiate services from market (nondurable) goods and from consumer durables (which they identify with household production) and find that, regardless of the assumptions made, the two groups of goods are very close substitutes, a result which would suggest setting $e=1$. BRW (1991) use cross-section data from the PSID to estimate an equation relating the relative allocation of time to the long run wage of the form

$$
\ln \left(\frac{H M_{i}}{H N_{i}}\right)=\alpha_{0}+\alpha_{1} \ln \left(w_{i}\right)+\epsilon_{i}
$$

They report an estimate of $e$ of about 0.6 , a value they believe underestimates the true $\epsilon$ because the panel underreports low-wage workers, which are the group with presumably a lower ratio of market to household hours. MRW (1993) obtain a value of $e$ of 0.385 (with standard error of 0.145 ) estimating by maximum likelihood a model with household production and a government sector. Finally, Rupert, Rogerson and Wright (1995), using PSID data, obtain values for $e$ ranging from -0.065 for single males to 0.355 for married couples. Here, as in BRW (1991), we use an intermediate value among existing estimates $(e=0.8)$ for our benchmark case and experiment with values in the range $[0.0,1.0]$ to examine how sensitive the results are to variations in this parameter.

This set of parameters yields steady state values for the consumption to market output ratio $(\mathrm{CM} / \mathrm{Y})$ and for the investment to output ratio $(\mathrm{I} / \mathrm{Y})$ of 0.70 and 0.29 , respectively. These values somewhat exceed the mean ratios for the US $(\mathrm{CM} / \mathrm{Y}=0.63$ and $\mathrm{I} / \mathrm{Y}=0.16)$ and the remaining largest 8 OECD countries $(\mathrm{CM} / \mathrm{Y}=0.61$ and $\mathrm{I} / \mathrm{Y}=0.26)$, but they are not too far off once we account for the fact that the model abstracts from taxes, government expenditure and details related to depreciation rates that would affect these ratios.

For the share of imports $M S$ and the elasticity of substitution of Armington aggregator $\rho^{-1}$ we use standard values suggested in the literature. Empirically, $M S$ varies substantially across countries, normally being higher for smaller countries. Ravn (1993) reports values ranging from 0.386 for Switzerland to 0.077 for the U.S.. BKK (1992) use two values (0.15 and 0.30 ) as a 'normal' and 'large' import share. Here we set $M S=0.225$, which is the cross sectional average of the largest 9 OECD countries for the benchmark case and check the sensitivity of the results to variations of MS in the range $[0.00,0.50]$ 
Values for $\rho^{-1}$ of 1-1.5 have been generally used in general equilibrium models of trade but they are believed to be lower bounds since estimates of this elasticity parameter are downward biased because of large measurement errors (see Whalley (1985)). Zimmermann (1994) obtains an expression for this elasticity in his model that depends on tariffs, transportation costs, import shares and terms of trade. The corresponding estimates for OECD countries he obtains are in the range $[0.6,13.5]$, averaging 5.4. Because of the variety of values, we 11se 1.5 as in BKK (1993) for the benchmark case and analyze the sensitivity of the results to changes in this parameter in the range $[0,5]$. Note that $(11)$, together with the import share and the value of $\rho$ chosen, pins down $\varpi_{i}$ as $\varpi_{1}=(1-M S)^{\rho}, \varpi_{2}=M S^{\rho}$ (see e.g. BKK (1993), p. 92).

Direct estimation of the parameters of the productivity process, i.e. the matrices $\mathrm{C}$ and $\mathrm{V}$, is not possible given the lack of time series data for household production variables. Therefore, we select these parameters to model different scenarios. In the benchmark case the shocks are completely symmetric across countries. The standard deviation of the shocks is set to 0.007 and the persistence parameter to 0.835 , which are averages of the estimated persistence of market technological shocks of the largest 9 OECD countries, the cross country correlation of the shocks is set to 0.25 and the spillover parameter between the two market technological shocks to 0.088 as in BKK (1993). Spillovers between the two household technologies, which could be interpreted as "fashions" transmitted from one country to the other, are set to zero because it is not clear if this transmission would be contemporaneous or with some lags. Cross-sector-cross-country spillovers as well as inter-sector-intra-country spillovers are also set to zero since the sign and the magnitude of these cross effects is unknown. Given the arbitrarity of these choices, we will also examine the sensitivity of the results to variations in the persistence parameter within the range $[0.5,1.0]$ and of the spillover parameter in the range $[0.00,0.15]$. Finally, we need to select the contemporaneous correlation of the household and market disturbances within a country. This parameter measures the technological incentive to shift economic activity across sectors, since lower values of the correlation generate more frequent sectoral productivity differentials. For the basic experiments we chose a value of 0.66 as in BRW (1991). Such a value is high and limits the contribution of the household sector to the dynamics of the model. In fact, MRW (1993) obtain an estimate of -0.18 for this correlation, which gives greater importance to the household sector in the model. Because of this uncertainty we perform sensitivity analysis to investigate 
how alternative settings of this parameter in the range $[-0.2,1.0]$ influence the results.

With these parameters we study three versions of the model: one where no household sector exists and the cycle is driven by disturbances to the market technology, one where both sectors are present and household production shocks are the sole source of disturbance and another where both types of shocks displace the economies from their steady state. For each model specification we consider three subcases (see Appendix): in the first one (named S1) shocks are uncorrelated across countries and there are no domestic or international spillovers. This setup mimics a situation where countries face idiosyncratic disturbances but move together over the business cycle because of trade interdependencies. The second setup (named S2) has correlated shocks and no spillovers. Here we try to mimic a typical situation in OECD countries where nations face somewhat common disturbances but there is very little evidence of lagged transmission of these shocks. In the third setup (named S3) we consider an economy with correlated shocks and spillovers, a scenario which may realistically resemble the economic environment of highly integrated economies like the EEC.

Because there are no distorting taxes or externalities, competitive allocations can be computed via a restricted formulation of the social planner problem and terms of trade can be determined using (11). To make the problem stationary we first detrend all variables but hours worked and leisure dividing them by the Hicks-neutral technological progress $\mathrm{X}_{h t}$. The stationary system is then solved for the steady state and the dynamics in response to the shocks are calculated by log-linearizing the first-order conditions around the steady state. We construct 100 samples of 96 periods (the number of quarters of our data) each time drawing shocks from a multivariate normal with covariance matrix equal to $V$ for each model specification. Each sample is Hodrick-Prescott filtered, standard deviations and cross correlations are computed, statistics are averaged over the 100 samples and the importance of sampling variability in the experiments is assessed. In all cases, the standard errors for the moments of interest are very small (of the order of 0.01-0.02). Therefore to save space, we only report the average value of the statistics. 


\section{The Results}

\subsection{Some Empirical Evidence}

In this subsection we briefly report and comment on a set of summary statistics of the data which we will use to informally compare the outcomes of our simulations (see Canova (1994) and Kim and Pagan (1995) for a more formal approach). In Canova and Ubide (1995) we have provided a more extensive documentation and discussion of the features of international business cycles for our data set. For complementary efforts, see also Backus and Kehoe (1992), Ravn (1993), Fiorito and Kollintzas (1994).

Since the model features two countries of equal size, we use quarterly seasonally adjusted from OECD Main Economic Indicators for U.S. and the aggregate European Community (E.U.), constructed by the OECD, for the period 1970:1 to 1993:4. We have also used as the second country a weighted average of Europe, Canada and Australia with no evident change in the statistics of interest. In this latter case we experimented with weights based on their share of output and their share of trade and the results are broadly invariant to this choice (see also Canova and Marrinan (1996)). We therefore report results where the second aggregate is the European Community.

To isolate the cyclical properties of the data, we follow the existing literature and use the Hodrick and Prescott (HP) filter with $\lambda=1600$. Several authors including Canova (1993), King and Rebelo (1993), Harvey and Jeager (1993) and Cogley and Nason (1995) have noted that this filter creates distortions in the compilation of basic statistics. However, because our task is to measure the incremental explanatory power of a particular theoretical feature (i.e. household production) over existing specifications, here we will restrict attention to this filter only. Ubide (1995) documented the properties of the data when also linear detrending and first order differences are used. We focus on estimates of the second moments of the data (standard deviations and contemporaneous domestic and international correlations) and we also report their standard error computed using a Newey and West procedure. The first two columns of table 1 shows the properties for the two aggregates we constructed.

Although we would have liked to build statistics for total (market and non-market) investments, we were unable to do so because data for consumer durables, which would closely proxy 
the definition of household capital we have given in the model, are not available on a consistent basis for European countries. Therefore, when we refer to investment we mean gross fixed private investment.

Consumption, employment, productivity and net exports are less volatile than output while investment and the terms of trade (TOT) are substantially more volatile in both countries. Also, as expected because of the averaging, ROW aggregates are less volatile than US aggregates except for net export and TOT. Note also that productivity, proxied here by the Solow residuals of a market production function, is less volatile than market output. It is well known that such a proxy may be very poor since it tends to capture factors other than productivity disturbances (see e.g. Evans (1992)). Our measure has additional problems because it is almost impossible, given existing data, to consistently measure inputs across countries (see Canova and Ubide (1995) for details). In any case, the fact that productivity is less volatile than market output indicates that there must be an internal mechanism amplifying the size of the fluctuations impinging on the economy. We also want to draw the attention to the variability of TOT in both countries: the size of this variability has been a stumbling block for previous models of the international business cycle: all models, in fact underreproduce this moment by a considerable amount.

All variables are procyclical with respect to output with the exception of net exports to output ratio which is countercyclical in both cases, and of TOT. Basic saving, constructed as $\mathrm{S}_{t}=\mathrm{Y}_{t^{-}} \mathrm{C}_{t^{-}} \mathrm{G}_{t}$, and investment are positively correlated in both countries even if the correlation for US variables is surprisingly low for this data set. In all cases, however, the correlation is significatively different from zero at the $1 \%$ confidence level.

International comovements in dicate that all variables positively comove across the two countries, that output is less correlated across countries than productivity or market hours, but is more correlated than consumption and investment. While the relative behavior of cross country consumption and output correlations have received substantial attention in the literature, the magnitude and the sign of the cross-country investment correlations constitute an important regularity previously underemphasized by the literature (see BKK (1995)). For the largest 9 OECD countries the size of pairwise investment correlation ranges between $[-0.01,0.77]$ with the median value around 0.45 . A successful model of the international business cycle must therefore be able to reproduce this important feature of the data in addition to standard ones. 


\subsection{Simulation Results}

The results of the simulation exercises when the two countries are identical are in the last eight columns of Table 1. When there are only household disturbances experiments S2 and S3 are identical (the intercountry spillovers of household disturbances is zero) and we only report one of them. The dynamic response of variables of the system is presented in Figure 1.

\subsubsection{A Model without the Household Sector}

Columns 3-4 of Table 1 (labelled Benchmark) present statistics for a model where the household sector is absent and fluctuations are driven by disturbances to the market technology and the first panel of Figure 1 shows the dynamics following the shock. This model specification, which is nested in our general setup by simply setting $e=\eta=0$ (see BRW(1991)), is standard and we only use it to compare the improvements obtained with alternative specifications. The model works well along many dimensions but, consistent with previous findings (see BKK (1995)), there are at least three aspects of the data which are mismatched, regardless of the experiment considered. First, net exports and TOT do not fluctuate enough. Second, consumption is more correlated than output across countries, while in the data the opposite is true. Third, investment is negatively correlated across countries while in the data, it is positively and significantly correlated. In judging the improvements produced by adding household production to the model we will focus primarily on these three aspects of the data ${ }^{1}$.

\subsubsection{A Model with Disturbances to Household Technology}

The results obtained when both sectors are present but only household production disturbances hit the economy are displayed in columns 6 and 7 of table 1 (labelled "Household Shocks"). The second panel of figure 1 shows the dynamics induced by these shocks.

As expected, the model generates higher relative variability in domestic consumption and investment relative to the benchmark case since agents can now substitute both intratemporally

\footnotetext{
${ }^{1}$ The statistics we present here are slightly different from those of BKK (1995, table 11.8 p.351) due to different values for the utility parameters (here $\tau=1$ while for them $\tau=2$ and we calibrate steady state hours while they calibrate the preference parameter), the lack of time to build, and a different share of imports to GDP (here $M S=0.225$ while for them $M S=0.15$ ). The qualitative features we emphasize, however, are independent of the exact parametrization chosen.
} 
and intertemporally. The relative variability of market hours and investment to output is similar to the one in the data, while the relative variability of consumption is twice as large. Note that investments vary more than in the benchmark case, because its composition among sectors fluctuates substantially over the cycle. The volatility of net exports is consistent with the actual values while the volatility of TOT is low and comparable to the one obtained in the benchmark case. To see why this happens, recall from (11) that the variability of TOT is related to the variability of the import ratio. For the experiments we have conducted the variability of the import ratio is approximately 10 times smaller than it is in the data. We conjecture that this has to do with the fact that the two countries are identical so that the import ratio is close to 1 in every period. Varying country size makes this ratio slightly more volatile, but not enough to match the actual one.

As in the benchmark case the model generates very high domestic correlations of market hours and consumption with output while the correlation of investment and productivity with output drops. This pattern of domestic correlations is easily accounted for by examining the impulse responses: a positive shock to the household technology changes the willingness to work in the market for a given wage, shifts the labor supply curve, lowers market consumption, market hours, market investments and market output while raising total investment. Such a disturbance therefore mimics a negative taste shock and induces a "recession" in the market sector. When the shock dies out total investment smoothly returns to its steady state and market consumption, market hours, market investment and market output move together to the steady state from below.

Net exports is less negatively correlated with output relative to the benckmark case because exports and imports are asyncronous when household production shocks drive the cycle. Note that with correlated shocks the correlation of net exports with output drops to -0.16 . Finally, the saving investment correlation is positive and significant, in agreement with Baxter and Crucini (1993), even when there are no direct cross country spillovers.

All experiments generate cross country consumption correlations which are in the range of values found in the data and are substantially lower than output correlations. The mechanism behind this fact can be easily discovered from the impulse responses: a shock to household production is a shock to a non-traded good sector. Therefore, while there are substantial ad- 
justments in the consumption bundle of domestic agents, this need not be the case in the consumption bundle of foreign agents if the household good constitutes a significant share of their consumption. This makes the cross country correlation of market consumption drop relative to the benckmark case even when the correlation of market output increases. This model specification, however, fails to deliver the positive comovements of investment we see in the data. Recall that a positive shock to the household technology raises total investment and causes a fall in all market variables. In the foreign country such a disturbance makes total investment drop substantially along with all market variables as the "negative" shock is transmitted from the domestic country. When the effects of the shock dies out, the recovery will be very similar in both countries. Thus, a positive household production disturbance generates unsyncronized comovements in the consumption of the market good and negative comovements of market investment across countries but highly positively correlated comovements in hours and outputs.

It is important to stress that the main channel of reallocation of domestic resources here is between consumption and hours in the household and market sector and not between consumption and investment as in the benchmark model. Also, the transmission of shocks across countries occurs both via trade in consumption and investment goods. Canova and Marrinan (1996) show that in a model with multiple goods and shocks to either the market technology or government expenditure the transmission of shocks via trade in consumption goods is minor. Our results suggest that when household disturbances drive the cycle, the opposite may occur.

In sum, the properties of the model are fairly robust across experiments. Contrary to models without the household sector, the current framework can produce a reasonable volatility for net export and international consumption and output correlations which are closer to the actual ones. However, it still fails to replicate the sign of investment correlations and the size of the volatility of the terms of trade ${ }^{2}$.

\footnotetext{
${ }^{2}$ To see what is the effect of having a deeterministic household production sector, we also conducted an experiment with deterministic household production and stochastic market technology disturbances. The results are contained in an appendix available upon request. Overall, the dynamics of the model are very similar to the case with only market technology disturbances. The major difference is that the model dsplays positive cross country investment correlations. This occurs because both investments respond positively, although with a lag, to market technology disturbances.
} 


\subsection{A Model with Disturbances to Market and Household Technologies}

The presence of disturbances to both sectors improves over previous results (summary statistics are in the last three columns of table 3). The standard deviations of market consumption and market hours are lower than in the case where only household shocks drive the cycle, are at realistic levels and net exports display the desired volatility. We also find high positive domestic correlations of consumption, hours, productivity and investment with output but, quantitatively, the correlations are reduced relative to the benchmark model. There is alo some improvements in the cyclical properties of trade variables: net exports is still countercyclical but its correlation with output is closer to those found in the actual data.

The most evident improvement over previous specifications appears in international comovements. The model is still able to reproduce the high saving-investment correlation and the output-consumption relationship but, with specifications $\mathrm{S} 2$ and $\mathrm{S} 3$, it also produces positive cross-country correlations of investments.

To understand why this occurs it is useful to examine the dynamics of this version of the model (right panel of figure 1). Positive shocks to both domestic technologies result in a transfer of resources to the production of the investment good and the household good, with a subsequent drop of domestic market consumption. In the foreign country such a combination of shocks causes an initial transfer of investment resources to the domestic country, a decrease in the production of the household good and an increase in the consumption of the market good. Depending on the correlation and spillover of shocks, these movements may be more or less persistent but even in the case of purely idiosyncratic shocks (case S1), the cross-country correlation of consumption is low.

If no household sector was present shocks to market technology would produce small cross country output correlations because investment and hours move in opposite directions in the two countries (see left panel of figure 1). When a household sector is present this feature disappears. Domestically, the initial rise in market hours and output due to shocks to the market technology is tempered by the decrease in market hours and output created by shocks to the household technology. In the foreign country the increase in market hours and output due to domestic household production shocks exceeds the decrease in market hours due to domestic market production shocks. Therefore, output and hours across countries will track each other better. 
When there is a household sector in the economy there will also be an initial increase in investment in the home country but differences across countries will be smaller relative to the two previous cases because the relative changes in market productivity across countries will be smaller. Hence, after a few periods both investment paths smoothly converge to their steady state from above and this induces positive cross country investment correlations.

The model still fails in replicating the volatility of the terms of trade. Stockman and Tesar (1994) show that when both technology and taste shocks are present in a model with nontradable goods, terms of trade variability is much larger than the one generated by this model. Two caveats are however necessary to compare our results and theirs. First, terms of trade variability is 10 times higher in their model relative ours even when only technology disturbances are present. Second, the disturbances hitting their economy have a variability which is substantially larger than ours and are asymmetric across sectors.

In conclusion, in agreement with Stockman and Tesar (1994), we find that a model with "supply" and "demand" shocks is both qualitatively and quantitatively superior to one where only "supply" disturbances exist, in the sense that it replicates features of the data that previous models were unable to generate while maintaining a good fit along standard dimensions.

\section{$5 \quad$ Sensitivity Analysis}

In this section we investigate whether the introduction of asymmetries in the processes for the technological disturbances alter our basic conclusions. In addition, we explore the robustness of the outcomes with respect to changes in the parameters describing the household sector, the stochastic process for technological disturbances and the extent of foreign trade. We focus attention on the volatility of terms of trade and net exports and the cross-country correlations of output, consumption and investment. Other statistics are broadly insensitive to changes in these parameters and are therefore neglected in this section. In all cases the remaining parameters are those of the model with both household and market disturbances.

\subsection{Asymmetries in the Disturbances}

We have conducted several experiments with asymmetric disturbances (see Canova and Ubide (1995) for details). In general, changes relative to the symmetric case are minor and, if anything, 
the performance of the model worsens in some of the cases. The most interesting outcomes are obtained when there are one-way spillovers from the domestic market technology to the domestic household technology and to the foreign market technology (see the appendix for the exact specification of the process for disturbances). This case mimicks a situation where country one is larger or more influential than the other and its market sector is substantially more important than its household sector. Three outcomes need to be noted. First, the risk sharing properties of the model are affected. With one-way spillovers output changes are asymmetric and this reduces international output correlations below international consumption correlations. For the same reason cross country investment correlations turn negative and significantly so in these experiments. Second, the variability of the terms of trade is slightly larger with one-way spillovers, but changes are small. Third, the savings-investment correlation slightly decreases in country one (the larger), and slightly rises in country two. Although the magnitude of the effect is small, it goes against the existing empirical evidence (see e.g. Baxter and Crucini (1993)). One reason for this outcome is that asymmetric spillovers create a wedge between domestic savings and investment: domestic investment does not benefit anymore from the induced increase in foreign investment because of asymmetries while domestic savings inherits the properties of output (and consumption) which are only mildly affected by the presence of asymmetries.

\subsection{Household Sector Parameters}

Figure 2 graphically displays how basic statistics change for different values of the elasticity of substitution between market and household goods (e), the capital share in the household production function (SKN), steady state hours in the household technology ( $\mathrm{HN}$ ) and the contemporaneous correlation of market and household disturbances (CNM).

The elasticity of substitution between market and household goods measures the willingness of agents to move resources across sectors: the closer is $e$ to 1 , the greater is the level of substitutability. The volatilities of market variables (except investment) remain stable for values of $e$ up to 0.9 but raise dramatically as $e$ approaches 1 . Such an increase is due to the more frequent transfer of resources across sectors while the reduction in the volatility of investment is due to the already discussed stabilizing effect that household production has on this variable.

For low values of $e$ the international investment correlation is about 0.5 . As $e$ increases, the 
instantaneous response of investment to a household production shock is larger, the convergence to the steady state slower and this lowers investment correlations which turn negative for values of $e$ close to one. Cross-country consumption correlations are non-monotonically related to the elasticity of substitution. For small values of $e$, consumption correlations are high, as in the benchmark model. When the substitution effect dominates the divergences of consumption paths across countries becomes larger and the cross country correlation decreases. However, for very high levels of $e$, the correlation rises again. The combined effect of shocks on consumption and investment makes the cross country correlations of outputs covary positively with $e$.

The capital share in household production function determines the relative contribution of employment and capital fluctuations to output fluctuations: as this share increases employment fluctuations contribute less to output variability and fluctuations of capital across sectors acquire a dominant role. Increasing SKN reduces the volatility of investment since shocks that reallocate resources between investment and consumption will also generate a higher need for capital in the household sector. However, changes in the volatilities of net exports and TOT are small. Disturbances that reallocate resources between consumption and investment will also make cross country investment correlations higher since investment paths will be more similar. As the share of capital increases, foreign investment decreases more and market consumption decreases (increases) more in the home (foreign) country so that cross country consumption correlations are lower. Finally, changes in this parameter have almost no effects on cross country output correlations.

Increasing steady state hours devoted to household activities should have approximately the same effect of increasing the share of capital in the household technology since in both cases the importance of the household sector in the economy increases. As expected, the more important the household sector is, the lower is the volatility of investment while no changes are evident in the volatilities of other variables, in particular net exports and TOT. The qualitative pattern of international comovements remains robust to changes in this parameter. Quantitatively, as the importance of the household sector increases, cross-country investment and output correlations increase and cross-country consumption correlations decrease.

The contemporaneous correlation of market and household disturbances is a measure of the technological incentive to shift resources across sectors. The higher the correlation is, the lower 
is the incentive to shift resources across sectors, and hence, the lower is the importance of the household sector in the economy. The results of these experiments confirm previous outcomes: the more important the household sector is, the smaller is the volatility of investment and the larger is the volatility of market variables. In addition, low or negative values of this correlation produce higher cross-country correlations of all variables but consumption.

In conclusion, results are robust to changes in the parameters of the household sector within a reasonable range. Only when the elasticity of substitution between market and household goods approaches one is the relative ordering of cross country consumption and output correlations altered and the cross country correlation of investment turns negative. Also, the volatility of net export and TOT appears to be stongly insensitive to the size of these parameters. In general, the more important the household sector is, the more satisfactory is the performance of the model along the dimensions of interest.

\subsection{Technological Disturbances}

Because the stochastic process for technological disturbances is not tied down to the data we examine the robustness of the results to variations in persistence and in the contemporaneous spillover parameters. The results of the investigation are reported graphically in figure 3 .

More persistent shocks increase the volatility of market variables, including net export and TOT, even though, relatively speaking, changes in the latter are small. Also, there is a nonlinear effect on the cross country output and investment correlations: on one hand, with more persistent shocks it takes more time to compensate the productivity differentials induced by idiosyncratic disturbances and this lowers international correlations. On the other, when shocks become more persistent the income effect dominates and both output and investment correlations increase dramatically. Cross country consumption correlations are unaffected by changes in this parameter.

Volatility measures are essentially unaltered by changes in the spillover parameters. International correlations, however, change. When no spillovers are present, a disturbance to household production causes domestic market consumption to decrease while household consumption and investment increase. The opposite occurs in the foreign country. With large spillovers consump- 
tion paths across countries track each other more closely because the initial drop in domestic consumption, induced by sectoral productivity differentials, is short lived. The effect on investment is the opposite and for higher values of spillover parameter the correlation across countries becomes negative as in the benchmark model. The cross country correlation of outputs, on the other hand, is non-monotonically related to the contemporaneous spillover parameter.

Hence, the qualitative properties of the model are insensitive to alternative specifications of the stochastic process for technological disturbances and only extreme values of the persistence parameter (greater than 0.9 ) or the contemporaneous spillover parameters (greater than 0.1) alter the qualitative features of the results.

\subsection{Trade Parameters}

Finally, we examine whether results depend on alternative settings of the import share (MS) and of the elasticity of substitution between local and imported goods in the production of the final market good $\left(\rho^{-1}\right)$. The results are graphically reported in figure 3 .

Variations in $M S$ have no significant effect on the volatilities of market variables, suggesting that the amplitude of the cycle does not significantly depend on trade, but generate significant effects on the volatility of investment and imports. As the share of imports increases, the increase in investment following positive technology disturbances becomes larger since it is easier to import capital goods. As a consequence, the volatility of net export also increases. From figure 3 it is clear that this increase is more marked for $M S$ larger than 0.25 . The volatility of TOT is also monotonically related to the import share increasing when MS increases, but even in the extreme case of $M S=0.45$, the volatility of TOT is only to 0.4 .

International comovements are also affected by the degree of openness of the countries. Increasing the import share affects the cross-country correlation of investment which becomes negative for $M S$ greater than 0.25 . The cross-country correlation of output is positively related to the import share, revealing the fact that even though trade may not be a decisive factor for the amplitude of cycles it is important for their international transmission. Similarly, because trade is mainly in capital goods, cross country consumption correlations decrease as $M S$ increases.

Finally, variations in the import share have some effects on two other correlations of interest. The correlation between the terms of trade and net exports displays the S-curve property noted 
by BKK (1995) for values of the import share in the range 0.10-0.35. For values of MS exceeding 0.35 an approximate tent-shape behavior appears. The savings-investment correlation is also affected by variations in the import share: the larger is MS, the less dependent a country is on domestic resources, so that the correlation between domestic savings and domestic investment decreases (down to 0.5 in the case of $\mathrm{MS}=0.45$ ). Because empirically the import share is inversely related to the size of the country, our results support the observation that the savings and investment correlation is higher for larger countries.

BKK (1993) show that the magnitude of $\rho^{-1}$ has important effects upon the comovements of net exports and the terms of trade in standard models. Our experiments indicate that variations of the elasticity of substitution in the final market good technology over the range $[0,5]$ have no effects on the main qualitative properties of the model. As we increase the complementarity of the goods, the volatility of the terms of trade increases but not sufficiently to produce values in the range of those observed in actual data. Also, the volatility of net export is inversely related to $\rho^{-1}$ since as $\rho^{-1}$ increases imports and exports become more correlated. The relative ordering of international consumption correlations is practically unaffected by changes in this parameter. Quantitatively, the cross country correlation of consumption and investment increases with $\rho^{-1}$.

\section{Conclusions}

In this paper we examine a two-country, two-good international RBC model with household production. We argue that household production adds important channels through which cyclical disturbances can be propagated both domestically and internationally, channels which are missing in a model with only a market technology, and can rationalize otherwise uninterpretable national taste shocks which have been previously used in the literature (see e.g. Stockman and Tesar (1994)).

We show that when both technology and household production shocks are present the model replicates several characteristics of international business cycles and account for previously unexplained features of the data. We also discuss whether the introduction of asymmetries in the driving forces of the model alters basic conclusions obtained with a symmetric process for the disturbances and identify those parameters which may be crucial in determining the sign and the magnitude of interesting statistics. 
Despite the relative success of our modelling effort for the "quantity puzzle" (see BKK (1995)), we are still unable to account for the "price puzzle", i.e. the fact that the volatility of the terms of trade in the model are so low relative to the data. With our best specifications the standard deviation of the terms of trade is still ten times smaller than the one of the actual data. We believe that the introduction of additional sources of shocks, such as nominal disturbances, or of a imperfectly competitive environment, either nationally or internationally, will be crucial in accounting for this additional aspect of international business cycles. 


\section{Bibliography}

Backus, D. and Kehoe, P., 1992, 'International evidence on the international properties of business cycles', American Economic Review, 82, 864-888.

Backus, D., Kehoe, P. and Kydland, F., 1992, 'International Real Business Cycles', Journal of Political Economy, 100, 745-775.

Backus, D., Kehoe, P. and Kydland, F., 1993, 'Dynamics of trade balance and the terms of trade: the J-curve?', American Economic Review, 84, 84-103.

Backus, D., Kehoe, P. and Kydland, F., 1995, 'International Business Cycles: Theory and Evidence', in Thomas F. Cooley, ed. Frontiers of Business Cycle Research, (Princeton University Press, Princeton).

Baxter, M. and Crucini, M., 1993, 'Explaining saving/investment correlations', American Economic Review, 83, 416-436.

Benhabib, J., Rogerson, R. and Wright, R., 1991, 'Homework in macroeconomics: household production and aggregate fluctuations', Journal of Political Economy, 99, 1166-1187.

Bonke, J., 1995, 'Education, work and gender: an international comparison', European University Institute, working paper EUF 95/4.

Canova, F., 1993 , 'Detrending and Business Cycle Facts', CEPR working paper 781.

Canova, F., 1994, 'Statistical Inference in Calibrated Models', Journal of Applied Econometrics, 9, S123-S143.

Canova, F. and Marrinan, J., 1996, 'Sources and propagation of international business cycles: common shocks or transmission?, Universitat Pompeu Fabra, manuscript.

Canova, F. and Ubide, A., 1995, 'Household Production and International Business Cycles', CEPR working paper 1115 .

Cardia, E., 1991, 'The dynamics of a small open economy in response to monetary, fiscal and productivity shocks', Journal of Monetary Economics, 28, 411-436.

Cogley, T. and Nason, J., 1995, 'The Effects of the HP Filter on Trend and Difference Stationary Time Series: Implications for Business Cycle Research', Journal of Economics Dynamics and Control, $19,253-278$.

Correia, I., Neves, J. and Rebelo, S., 1992, 'Business cycles in Portugal: theory and evidence', in J.F. do Amaral, D. Lucena and A.S. Mello, eds. The Portuguese economy towards 1992, Kluver Press, Norwell, MA).

Devereux, M., Gregory, A. and Smith, G., 1992, 'Realistic cross-country consumption correlations in a two-country, equilibrium, business cycle model', Journal of International Money and Finance, 17, 36-54.

Eichenbaum, M. and Hansen, L.P., 1990, 'Estimating models with intertemporal substitution using aggregate time series data', Journal of Business and Economic Statistics, 8, 44-66. 
Eisner, R., 1988, 'Extended accounts for national income product', Journal of Economic Literature, $26,1611-1684$.

Evans, C., 1992, 'Production shocks and real business cycles', Journal of Monetary Economics, 29, 191-208.

Fiorito, R. and Kollintzas, T., 1994, 'Stylized facts of business cycles in the G7 from a real business cycle perspective', European Economic Review, 38, 236-269.

Fisher, J., 1992, 'Relative prices, complementarities and comovements', mimeo, Northwestern University.

Greenwood, J. and Hercowitz, Z., 1991, 'The allocation of capital and time over the business cycle', Journal of Political Economy, 99, 1188-1214.

Greenwood, J., Rogerson, R., and Wright, R., 1993, 'Putting home economics into macroeconomics', Federal Reserve Bank of Minneapolis Quarterly Review, Summer, 1-17.

Harvey, A. and Jaeger, 1993, 'Detrending, stylized facts and the business cycle', Journal of Applied Econometrics, 8, 21-54.

Hill, M., 1985, 'Patterns of time use', in Juster and Stafford eds. Time, goods and well-being, Ann Arbor, University of Michigan.

Hodrick, R. and Prescott, E., 1980, 'Post-war U.S. business cycles: An empirical investigation', GSIA, Carnegie-Mellon University, manuscript.

Juster, T. and Stafford, F., 1990, 'The allocation of time: empirical models, behavioral models and problems of measurement', University of Michigan, working paper.

Kim, and Pagan, A., 1995, 'The econometric analysis of calibrated macroeconomic models', in H. Pesaran and M. Wickens, (eds.), Handbook of Applied Econometrics, (Kluwer Press, London).

King, R., and Rebelo, S., 1993, 'Low frequency filtering and Real Business Cycles', Journal of Economics Dynamics and Control, 17, 207-231.

Kydland, F. and Prescott, E., 1982, 'Time to build and aggregate fluctuations', Econometrica, 50, 1345-1370.

Long, J. and Plosser, J., 1983, 'Real business cycles', Journal of Political Economy, 91, 39-69

Marrinan, J. (1995), 'Government Consumption and Private Consumption Correlations', Universitat Pompeu Fabra, manuscript.

McGrattan, E. , Rogerson, R. and Wright, R., 1993, 'Household production and taxation in the stochastic growth model', Federal Reserve Bank of Minneapolis, Staff Report 166.

Mendoza, E., 1991, 'Real business cycles in a small open economy', American Economic Review, 81, 
797-818.

Ravn, M., 1993, 'International business cycles: how much can standard theory account for?', forthcoming, Journal of International Money and Finance.

Rios-Rull, J.V., 1993, 'Working in the market, home production and the acquisition of skills: a general equilibrium approach', American Economic Review, 84, 893-907.

Rupert, R, Rogerson, R. and Wright, R., 1995, 'Estimating substitution elasticities in household production models', Economic Theory, 6, 179-193.

Stockman, A. and Tesar, L., 1994, 'Tastes and technology in a two-country model of the business cycle: explaining international comovements', American Economic Review, 85, 168-185.

Ubide, A., 1995, 'On International Real Business Cycles', unpublished Ph. D. dissertation, European University Institute.

Van Wincoop, E. and Marrinan, J., 1994, 'Private and Public Saving and Investment', IGIER working paper.

Whalley, J., 1985, Trade liberalization among major trading areas, (MIT Press, Cambridge, MA).

Zimmermann, C., 1994, 'Technology innovations and the volatility of output: An international perspective', GSIA, Carnegie Mellon University, manuscript. 


\section{APPENDIX}

\section{BENCHMARK PARAMETER VALUES}

\begin{tabular}{ccccccccccc}
\hline$\beta$ & $\delta$ & $\Pi$ & $\tau$ & $\theta$ & $\eta$ & $a$ & $b$ & $e$ & $M S$ & $1 / \rho$ \\
\hline 0.98 & 0.025 & 0.5 & 1.0 & 0.36 & 0.08 & 0.35 & 0.63 & 0.8 & 0.22 & 1.5 \\
\hline
\end{tabular}

\section{PROCESS FOR THE DISTURBANCES: BASIC EXPERIMENTS}

- S1: Domestically correlated shocks without spillovers.

\begin{tabular}{|c|c|c|c|c|c|c|c|c|c|}
\hline \multicolumn{5}{|c|}{ C MATRIX } & \multicolumn{5}{|c|}{ CORRELATION MATRIX } \\
\hline & $A N 1$ & $A N 2$ & $A M 1$ & $A M 2$ & & $A N 1$ & $A N 2$ & $A M 1$ & $A M 2$ \\
\hline$A N 1$ & 0.835 & 0 & 0 & 0 & $A N 1$ & 0.007 & & & \\
\hline$A N 2$ & 0 & 0.835 & 0 & 0 & $A N 2$ & 0 & 0.007 & & \\
\hline$A M 1$ & 0 & 0 & 0.835 & 0 & $A M 1$ & 0.66 & 0 & 0.007 & \\
\hline$A M 2$ & 0 & 0 & 0 & 0.835 & $A M 2$ & 0 & 0.66 & 0 & 0.007 \\
\hline
\end{tabular}

- S2: Domestically and sectorially correlated shocks without spillovers.

\begin{tabular}{|c|c|c|c|c|c|c|c|c|c|}
\hline \multicolumn{5}{|c|}{$\mathrm{C}$ MATRIX } & \multicolumn{5}{|c|}{ CORRELATION MATRIX } \\
\hline & $A N 1$ & $A N 2$ & $A M 1$ & $A M 2$ & & $A N 1$ & $A N 2$ & $A M 1$ & $A M 2$ \\
\hline$A N 1$ & 0.835 & 0 & 0 & 0 & $A N 1$ & 0.007 & & & \\
\hline$A N 2$ & 0 & 0.835 & 0 & 0 & $A N 2$ & 0.25 & 0.007 & & \\
\hline$A M 1$ & 0 & 0 & 0.835 & 0 & $A M 1$ & 0.66 & 0 & 0.007 & \\
\hline$A M 2$ & 0 & 0 & 0 & 0.835 & $A M 2$ & 0 & 0.66 & 0.25 & 0.007 \\
\hline
\end{tabular}

- S3: Dommestic and sectorially correlated shocks with spillovers.

\begin{tabular}{|c|c|c|c|c|c|c|c|c|c|}
\hline \multicolumn{5}{|c|}{ C MATRIX } & \multicolumn{5}{|c|}{ CORRELATION MATRIX } \\
\hline & $A N 1$ & $A N 2$ & $A M 1$ & $A M 2$ & & $A N 1$ & $A N 2$ & $A M 1$ & $A M 2$ \\
\hline$A N 1$ & 0.835 & 0 & 0 & 0 & $A N 1$ & 0.007 & & & \\
\hline$A N 2$ & 0 & 0.835 & 0 & 0 & $A N 2$ & 0.25 & 0.007 & & \\
\hline$A M 1$ & 0 & 0 & 0.835 & 0.088 & $A M 1$ & 0.66 & 0 & 0.007 & \\
\hline$A M 2$ & 0 & 0 & 0.088 & 0.835 & $A M 2$ & 0 & 0.66 & 0.25 & 0.007 \\
\hline
\end{tabular}

PROCESS FOR THE DISTURBANCES: EXPERIMENTS WITH ASYMMETRIES

- E1: One way spillovers in both technologies.

\begin{tabular}{|c|c|c|c|c|c|c|c|c|c|}
\hline \multicolumn{5}{|c|}{ C MATRIX } & \multicolumn{5}{|c|}{ CORRELATION MATRIX } \\
\hline & $A N 1$ & AN2 & $A M 1$ & $A M 2$ & & $A N 1$ & $A N 2$ & $A M 1$ & $A M 2$ \\
\hline$A N 1$ & 0.835 & 0 & 0 & 0 & $A N 1$ & 0.007 & & & \\
\hline AN2 & 0 & 0.835 & 0 & 0 & $A N 2$ & 0.25 & 0.007 & & \\
\hline$A M 1$ & 0.088 & 0 & 0.835 & 0.088 & $A M 1$ & 0.66 & 0 & 0.007 & \\
\hline$A M 2$ & 0 & 0 & 0 & 0.835 & $A M 2$ & 0 & 0.66 & 0.25 & 0.007 \\
\hline
\end{tabular}

- E2: One way spillovers, stronger in market technology.

\begin{tabular}{|c|c|c|c|c|c|c|c|c|c|}
\hline \multicolumn{5}{|c|}{ C MATRIX } & \multicolumn{5}{|c|}{ CORRELATION MATRIX } \\
\hline & $A N 1$ & $A N 2$ & $A M 1$ & $A M 2$ & & $A N 1$ & $A N 2$ & $A M 1$ & $A M 2$ \\
\hline$A N 1$ & 0.835 & 0 & 0 & 0 & $A N 1$ & 0.007 & & & \\
\hline$A N 2$ & 0 & 0.835 & 0 & 0 & $A N 2$ & 0.25 & 0.007 & & \\
\hline$A M 1$ & 0.004 & 0 & 0.835 & 0.088 & $A M 1$ & 0.66 & 0 & 0.007 & \\
\hline$A M 2$ & 0 & 0 & 0 & 0.835 & $A M 2$ & 0 & 0.66 & 0.25 & 0.007 \\
\hline
\end{tabular}

On the main diagonal of the correlation matrix are standard deviations, on the lower half correlations. 